\title{
La tolerancia religiosa en la Constitución de 1876. Análisis de la campaña de protesta
}

\author{
María luisa Ollero Prieto *
}

En contraposición a los turbulentos años anteriores, el periodo histórico que conocemos con el nombre de Restauración fue una etapa de estabilidad y fecundidad políticas largamente duraderas. El marco histórico de la monarquía borbónica restaurada quedará fijado en una nueva constitución, la del año 1876, fruto del consenso de las principales fuerzas políticas, y, por este mismo carácter, conciliador de las diferentes posturas existentes en el seno de la sociedad española de la época.

Al buscar la unidad de los españoles, su coincidencia y conciliación, esta nueva Ley Fundamental va a producir, sin embargo, una enorme polémica social al admitir en su artículo 11 la tolerancia de cultos en España. Los enfrentamientos y divisiones que se originarán a propósito de este artículo lo van a convertir en la clave de la nueva constitución y en un verdadero test para el catolicismo hispano.

Se iba a la tolerancia de cultos desde la libertad religiosa total existente en aquel momento y fruto de la revolución de 1868; para muchos españoles esto significa un drástico recorte a una de las libertades individuales conquistadas entonces, $y$, aunque estarían dispuestos a aceptar con reservas esta tolerancia, nunca, desde luego, a volver a la unidad católica decretada por ley.

Ésto era, sin embargo, a lo que aspiraban una buena parte de los católicos del pais, para quienes el proyecto de tolerancia religiosa decep-

\footnotetext{
* Dep. de Historia Contemporánea. Universidad Nacional de Educación a Distancia.
} 
cionaba sus expectativas de retorno a la situación religiosa anterior al período revolucionario, haciéndoles dudar de la compatibilidad del sistema restaurado y el catolicismo.

La ofensiva del catolicismo intransigente en pro de la unidad católica se concretará en diferentes acciones. Una de ellas va a ser la batalla dialéctica que van a plantear sus partidarios en las propias cortes constituyentes a fin de conseguir la reforma del artículo; otra la campaña desatada en la prensa adicta, que tendrá diferentes matices según sea la tendencia concreta a la que el medio informativo estuviera adscrito; una mas, la toma de postura en el conflicto por parte de la Santa Sede, plasmada en una controversia diplomática que va a durar hasta septiembre de 1876, en que Roma aceptará, no sin reservas, el principio de tolerancia religiosa; y finalmente, a remolque suyo, las medidas tomadas por la jerarquia eclesiástica española que se van a concretar en una campaña institucional y otro popular, con el envío de miles de exposiciones al Congreso y al Senado pidiendo la abolición del artículo 11 en base al derecho de petición recogido por las leyes.

Esta toma de postura de la jerarquía hispana contra la tolerancia religiosa y el apoyo que encuentra en la sociedad española es el tema del que se ocupa precisamente este artículo.

\section{LA CAMPAÑA INSTITUCIONAL}

La discusión del artículo 11 de la futura constitución, que abría la posibilidad, con su aprobación, de una tolerancia religiosa no deseada en absoluto por la Santa Sede ni por las altas jerarquías eclesiásticas españolas, movilizó de una manera activa al episcopado en contra de tal proyecto, iniciándose una acción colectiva de la cúpula religiosa que se plasmó en el envio de una serie de exposiciones dirigidas primero al Rey ${ }^{1}$ y más tarde al Congreso y al Senado firmadas por los arzobispos y obispos de cada provincia eclesiástica ${ }^{2}$.

Los primeros documentos episcopales, al estar dirigidos al Rey, tienen un marcado acento personal, recordando a Alfonso XII su condición

\footnotetext{
1 Publicadas integramente por la prensa de la época, ver La Cruz, volumen 1 (1876), revista considerada en aquel tiempo el órgano oficioso del episcopado.

${ }^{2}$ Archivo del Senado. Comisión de Peticiones, Legislatura 1876, legajo 649, Autoridades, exps. $n .{ }^{\circ} 1,3,4,5,6,8,10,36$ y 37 .
} 
de monarca católico, algo que le obliga a gobernar católicamente sus estados; el carácter también católico de la dinastía de la que él es heredero, y las esperanzas que creó su restauración en el trono español entre los católicos de este país, quienes confiaban en una restauración religiosa similar a la política que enterrase la acción anticlerical del sexenio anterior.

Este inevitable recuerdo a la revolución de 1868 sirve, por otra parte, para recordar que si la Iglesia española sufrió con ella, mucho más hubo de sufrir la Corona, y asi como ahora está restaurada la dinastía, asi debe serlo también la antigua unidad religiosa; en resumen, al rey se le viene a decir que la libertad religiosa debe ser algo tan provisional como lo fue el sistema que la implantó, y que la monarquia no puede apoyar ahora algo que también ayudó a derrocarla.

Aquellas otras exposiciones que se enviaron más tarde a las Cortes son, en términos generales, muchos más extensas que las enviadas al Rey, y cargan el acento más en aspectos doctrinales y teológicos que en los estrictamente políticos, sin que falten éstos, sobre todo en lo que se refiere al cumplimiento del Concordato de 1851, que se considera violado por el proyectado artículo 11.

Una primera cosa salta a la vista: en ninguno de los documentos se distingue entre libertad de cultos y tolerancia religiosa: ambos términos son usados de modo equivalente por todos los prelados para declarar que eso es algo inadmisible por la Iglesia católica. La distinción, sin embargo, estaba clara para el gobierno: Cánovas había hablado en el Congreso en un momento de la discusión del artículo de que no se podía ir contra los hechos establecidos, y que toda la legislación del país estaba basada desde hacia ocho años "no en la tolerancia, sino en la absoluta libertad religiosa»; más tarde, en el Senado, también distinguirá que el artículo 11 no afirmaba el establecimiento de cultos disidentes, sino sólo que no se perseguiría, ni aplicaría el código penal a los actos de los cultos disidentes.

Hay, ciertamente, una gran diferencia entre este artículo que ahora se discute y el 21 de la constitución de 1869; si en este último se puede hablar de libertad religiosa puesto que el Estado no se declara confesional y permite la total libertad de cultos "sin más limitaciones que las reglas universales de la moral y el derecho", en el que ahora se está discutiendo el Estado si se declara confesional -católico, apostólico y romano- y no se permiten manifestaciones públicas de otro culto diferente, aunque "nadie será molestado en el territorio español por sus opiniones religiosas ni por el ejercicio de su respectivo culto". Es decir, 
el Estado tiene una personalidad religiosa definida, pero "tolera" que sus ciudadanos tengan otras diferentes. Esto es lo que se puede considerar la tolerancia religiosa, bien diferente de la plena libertad consagrada en el año 1869, en que el Estado, para empezar, no es confesional, y admite todos los cultos con igual derecho.

Está claro que para la jerarquía eclesiástica la cuestión religiosa, tal como es contemplada en el proyecto constitucional, continúa la obra revolucionaria de la librecultista constitución del año 69, puesto que entiende que la tolerancia no es más que una libertad de cultos encubierta, algo que un gobierno verdaderamente católico no puede tolerar. Siguiendo a Balmes, esta tolerancia religiosa es considerada un mal en si mismo, el sufrimiento de algo que se conceptúa malo, pero que se cree conveniente no castigar. En este punto doctrinal concreto Jaime Balmes es el autor al que se recurre con más frecuencia, aún sin ser citado, ya que en su obra El protestantismo comparado con el catolicismo había tratado extensamente los temas de la libertad de cultos, la tolerancia civil y la intolerancia religiosa ${ }^{3}$.

La distinción entre libertad religiosa y simple tolerancia ya había tratado de establecerse en medio de una ardiente polémica desde mediados del año anterior, cuando se observa en el seno de la Asamblea de Notables, y dentro del grupo de los que se oponen a recoger en el futuro texto constitucional la libertad de cultos, una clara división entre los que aceptarian que se contemplara cierta tolerancia y aquellos que la rechazan total y sistemáticamente.

Dentro de estos últimos se encuentran algunos personajes que más tarde, como diputados y senadores, seguirán defendiendo en ambas cámaras la unidad católica de España: el Marqués de Pidal, Mon y Mayans, Carramolino, el Marqués de Corvera...; dentro de los primeros figuran el unionista Martín Herrera, para quien la tolerancia es un mal necesario, un sacrificio inevitable; el moderado Dominguez, que postula la tolerancia sólo para los extranjeros, o el también ex-unionista Suárez Inclán, que aunque no acepta la libertad de cultos, si aceptaria la tolerancia ${ }^{4}$.

Los diarios y revistas de entonces se harán eco de esta polémica y darán acogida en sus páginas a las diferentes posturas, según sea su signo o preferencia política. En uno de estos diarios se encuentra precisamente la distinción más clara desde el punto de vista católico de lo

${ }^{3}$ Balmes, Jaime, Obras completas. Tomo IV. Madrid. Biblioteca de Autores Cristianos.

${ }^{4}$ El Consultor de los Párrocos, n. ${ }^{\circ} 34,22-V \mid 1-1875$, pág. 270. 
que es la tolerancia y lo que es la libertad religiosa: «... tolerancia es condescendencia que en ciertos y determinados casos, y por altísimas razones, pueden tener los católicos, sufriendo que algunas sectas, muy pocas, ejerzan su culto sin propagar sus errores... otra cosa es la libertad de cultos, principio racionalista, fruto de las revoluciones modernas que se funda en los errores absurdos de la soberanía de la razón y de la libertad de pensamiento, que hace de igual condición y da los mismos derechos a la religión y a las sectas... " 5 .

En conclusión, para el catolicismo intransigible si mala es la libertad de cultos, mala es también la simple tolerancia, de ahí que ambos supuesto sean considerados igualmente nefastos.

Frente a esta postura empecinada, Sagasta afirmará en el Congreso ${ }^{6}$ que aunque él fuera el único español que deseara la tolerancia, ésta tendrá que ser aprobada porque “... ni un individuo, ni muchos, ni el mundo entero, tienen el derecho para forzar mi alma y para violentar mi espíritu, haciéndome creer lo que no creo y adorar lo que no adoro. La cuestión de conciencia es una cosa perfectamente individual, que no afecta más que a la persona... ".

Si hoy nos parece que aquellos prelados adoptaron una actitud cerada y excesivamente intransigente ante un articulo que puede considerarse muy moderado para lo que se estilaba entonces por Europa, hemos de tener en cuenta, también, que aquellos hombres no hacian más que seguir las directrices emanadas de la Santa Sede, gobernada por el Papa Pío IX, el autor del Syllabus ${ }^{7}$. En el Breve enviado al cardenal Moreno, arzobispo de Toledo $^{8}$, con fecha 4 de marzo de 1876, es decir, en plena discusión parlamentaria de la constitución. Pío IX decia a propósito del articulo 11: «...declaramos que dicho artículo, que se pretende proponer como ley del reino, y en el que se intenta dar poder y fuerza de derecho público a la tolerancia de cualquier culto no católico, cualesquiera que sean las palabras y la forma en que se proponga, viola del todo los derechos de la verdad y de la religión católica" ${ }^{9}$.

El Siglo Futuro, 5-VI-1875.

DSC 12 de mayo de 1876.

7 SANZ de Diego, Rafael, "La actitud de Roma ante el artículo 11 de la constitución de 1876". Hispania Sacra, 1975.

${ }^{8}$ La España, 21-111-1876.

${ }^{9}$ Hubo otras cartas enviadas en esos meses por Pio IX a prelados y personalidades españolas en contra de la tolerancia de cultos, aunque ninguna de ellas gozara de la resonancia obtenida por el Breve del cardenal Moreno (resonancia que tenia otros motivos, como que su publicación coincidió con el final de la guerra carlista, lo que fue interpretado por ciertos sectores como una llamada a la resistencia). 
En realidad, el objetivo de esta campaña institucional era doble: por un lado, mediante este envío de protestas altamente cualificadas - las del Papa incluidas- la diplomacia vaticana presionaba fuertemente al Gobierno canovista, comprometido hasta la médula en no anular la libertad de conciencia obtenida años atrás; por otro, de este modo la jerarquia iluminaba doctrinalmente con estos documentos a sus bases religiosas, marcaba la senda oficial del catolicismo de entonces y daba los argumentos y razones correctos por los que todo buen católico debía guiarse en esta cuestión.

Básicamente estas razones y argumentos estaban recogidos de forma sistemática en el Syllabus de Errores del año 1864. Este polémico documento, frontera y divisoria durante mucho tiempo de los católicos del mundo, no sólo los españoles, había condenado todas las tendencias secularizadoras del siglo y los "errores" derivados de la revolución francesa de 1789; el catolicismo era, según su proposición 80 , incompatible con el liberalismo, doctrina en cuyo nombre se intenta secularizar la religión, la educación y la vida social toda. En el Syllabus se condenaban, entre otros, la libertad religiosa, y aún la simple tolerancia, pues era un «error» considerar a todas las religiones iguales y con los mismos derechos.

Las exposiciones del episcopado, que son publicadas por la prensa y leídas por los párrocos en sus sermones dominicales, cumplen la función de vulgarizar estas ideas, y dan al católico un andamiaje intelectual básico con el que apuntalar dogmáticamente su oposición al artículo 11.

\section{LA CAMPAÑA DE APOYO POPULAR}

Uno de los argumentos más empleados por la jerarquía para oponerse a la tolerancia de cultos es que va contra el sentir general del pueblo español, mayoritariamente católico. En base a esta afirmación se va a montar una campaña de apoyo popular con recogida de firmas por los pueblos y parroquias.

Son las autoridades religiosas, precisamente, quienes se encargarán de movilizar al ciero y feligreses de sus respectivas diócesis en un proceso organizativo que sigue el siguiente esquema: los obispos darán las instrucciones y consigrias; sus organos de difusión serán los Boletines Eclesiásticos de su correspondiente provincia; los párrocos, desde el púlpito, van a ser los agentes activos y, finalmente, los feligreses más adic- 
tos y de confianza los encargados de ayudar al sacerdote en la tarea de recogida de firmas.

Desde la parroquia, célula territorial religiosa básica, se harán llegar directamente los pliegos firmados al obispado, desde cuya secretaria se remitirán por bloques al Congreso y al Senado... Este esquema organizativo explica que lleguen a las Cámaras exposiciones desde las más apartadas aldeas del país, donde posiblemente ni se tuviera conocimiento de que se estaba debatiendo una nueva constitución, o que aparezcan varias exposiciones diferentes de una misma localidad (es el caso, sobre todo, de las capitales de provincias y grandes ciudades), puesto que cada párroco se moviliza de forma individual y autónoma dentro de su ámbito parroquial.

El envío de exposiciones y peticiones a las Cortes, al Gobierno y al monarca por motivos religiosos no era en 1876 ningún hecho nuevo. En realidad, el catolicismo español tuvo durante el siglo XIX un tono militante y activo muy señalado. En una relación somera, y ciñéndose tan solo a la segunda mitad del siglo, se pueden señalar las campañas organizadas durante el bienio progresista en contra de la nonnata constitución de 1855; la que diez años más tarde se organizó para protestar por el reconocimiento del reino de Italia por el gobierno español, y la que en 1868 reclamaba contra los atentados cometidos por las Juntas Revolucionarias contra la Iglesia, condenando los principios de la revolución y exigiendo la observancia del Concordato de 1851.

Con todo, el antecedente más próximo y más claro de la campaña que se organiza ahora fue aquella otra organizada contra las constituyentes de 1869 en defensa de la unidad católica, amenazada por el artículo 21 de la constitución que se estaba elaborando, que suponía la plena libertad religiosa por primera vez en España.

La Asociación de Católicos, organización que se crea en el mes de diciembre de aquel mismo año para defender los derechos de la Iglesia amenazados por la revolución triunfante, y hacer frente a la amenaza anticlerical, propone unificar todas las manifestaciones de protesta contra la libertad de cultos que se pretende aprobar, en una Petición Unificada, que se haría llegar al Parlamento a fin de que pesara en el ánimo de los legisladores a la hora de decidir en la cuestión religiosa abierta en aquellas constituyentes ${ }^{10}$. La Asociación consiguió recoger alrededor de cua-

${ }^{10}$ Rodriguez, Jerónimo, La sociedad española ante la libertad religiosa, 1869. Valoración cuantitativa. Memoria de Licenciatura. Dept. de Historia Contemporánea. Madrid, UNED. 
tro millones de firmas procedentes de más de 10.000 pueblos de España. Si se tiene en cuenta que la población española ronda por aquellos años los 16 millones de habitantes, se puede hablar de un gran éxito de organización y de respuesta.

La Asociación de Católicos, que se mantiene funcionando pese a los años transcurridos, no va a ser en esta ocasión el organismo encargado de canalizar la campaña. En la Exposición enviada a las Cortes de fecha 6 de abril de $1876^{11}$ considera que su actuación no es necesaria, recuerda las razones que la impulsaban a pedir el establecimiento de la unidad católica en el año 69, las mismas expuestas a su majestad el Rey por su Junta Superior ya en febrero de 1875 , y afirma que si hace años consiguió reunir tal cantidad de firmas en contra de la libertad de cultos "... no le sería difícil hoy, si lo creyera necesario, reunir otras tantas, pues ninguno de los que firmaron entonces, se negaría a firmar ahora".

Los redactores de esta exposición se equivocan en buena parte: las circunstancias que vive el pais son bien diferentes de aquellas; en lo político se va del desorden a la estabilidad, y el nuevo texto legal que se está preparando recoge un necesario espíritu de conciliación, con una zona del territorio nacional en plena guerra civil dinástico-religiosa (en las provincias vascas y en Navarra, en una parte de Aragón y Cataluña, ahora no se podrían recoger firmas porque las únicas campañas que se pueden realizar alli son las militares); y en lo religioso, el catolicismo español se encuentra ahora profundamente dividido: no resulta tan fácil llegar a un acuerdo entre los católicos intransigentes y aquellos otros que consideran que el catolicismo es compatible con la tolerancia religiosa y la libertad de enseñanza ${ }^{12}$.

Entre discusiones y acusaciones mútuas, cualquier clase de iniciativa común entre las organizaciones laicas acaba resultando inútil. Es por ello por to que serán las autoridades religiosas quienes acaban poniéndose al frente de la campaña.

La campaña de apoyo popular con envío de exposiciones al Congreso y al Senado pidiendo la conservación de la unidad católica en España se inició en el mes de febrero de 1876 y finalizó en la primera mitad del mes de junio siguiente; el tiempo empleado en la recogida de firmas varió mucho de un lugar a otro, puesto que aunque en algunas

"Exposición a las Cortes de la Junta superior de la Asociación de Católicos de España. AS Leg. 649, exp. n. ${ }^{\circ} 46$.

12 Campomar, Marta, La cuestión religiosa en la Restauración. Santander. Instituto de Estudios Menéndez Pelayo, 1984. 
circulares los obispos piden a sus párrocos que la campaña se haga con la mayor brevedad posible, no se fijan a los sacerdotes plazos concretos para hacerlo.

Tampoco hay un texto único para todas estas exposiciones. Su redacción se deja a veces al criterio del sacerdote, sin ningún tipo de indicación sobre el texto (caso, por ejemplo, del obispado de Badajoz); en otras, como en el caso del obispado de Cartagena, se indica simplemente que se debe pedir la conservación de la unidad católica con "breves y sencillas palabras". Sin embargo, en la mayoría de los casos el obispo envía al párroco el texto de la exposición para que éste sólo tenga que copiarla y recoger luego las firmas de apoyo de sus feligreses.

La comunicación entre obispo y sacerdote se realiza, como queda dicho a través de los Boletines Eclesiásticos de la diócesis, que eran el órgano oficial de divulgación del magisterio episcopal ${ }^{13}$. Al tomar partido en la cuestión religiosa en contra del gobierno alineándose con las tesis de la Santa Sede, estos boletines van a ser vistos como verdaderas publicaciones de propaganda y controversia sobre cuestiones que afectan al Estado, por lo que algunas autoridades provinciales llegarán a prohibirlos o secuestrarlos.

Este fue el caso del secuestro y posterior permiso de circulación del Boletín Eclesiástico del Arzobispado de Toledo correspondiente a la segunda semana de enero del año 76, o el secuestro de la pastoral del obispo de Calahorra sobre la unidad católica, o la prohibición del gobernador civil de Zamora de la Carta Pastoral del obispo de aquella diócesis, asi como la amenaza a su editor de cerrarle la imprenda por tres meses, todo ello en el mismo mes de enero ${ }^{14}$.

Esta va a ser la tónica general de actuación del poder civil, por cuanto se dan órdenes para que los Boletines sean considerados como otra publicación periódica cualquiera, sujetándose a la legislación de imprenta vigente - Real Decreto de 31 de diciembre de 1875- teniendo que enviar un ejemplar previo al gobernador civil ${ }^{15}$.

13 Comenzaron a publicarse de forma regular desde los años cincuenta, y solian tener periodicidad semanal, aunque podian salir cuando el obispo lo estimase oportuno.

${ }_{14}$ Una relación de estos hechos aparece en el diario La España de 21-1-1976, en el artículo titulado "Las coacciones".

${ }^{15}$ La España, 1-1-1876. Un suelto recoge ésta y otras informaciones relativas a la actuación de las autoridades civiles en este asunto. 
INCIDENCIAS Y DIFICULTADES

La campaña de recogida y envio de firmas a las Cortes en principio resulta un éxito, por cuanto bien pronto empiezan a llegar al palacio del Congreso y al Senado numerosas exposiciones avaladas por miles de firmas; pero la campaña va a estar llena de sobresaltos e incidencias.

No cabe duda de que en algunos lugares las autoridades civiles ejercieron cierta coacción para evitar el éxito de la operación: la prensa, los mismos documentos y hasta los Diarios de Sesiones de las Cámaras recogerán las protestas de los afectados; por contra, también se registran las quejas que motivan el exceso de celo de algunos sacerdotes y el empleo de métodos poco ortodoxos para conseguir las adhesiones.

Las acusaciones a la actuación del clero que han sido recogidas son de carácter vago e impreciso; al no darse nombres de personas ni de lugares queda siempre la duda de cuánto de verdad hay en ellas y cuánto de exageración interesada. Cuando aún no habia comenzado a discutirse el artículo 11 en el Congreso, ya el diputado de la minoría constitucional, Núnez de Arce, preguntaba al ministro de la Gobernación qué se estaba haciendo para controlar los medios empleados por los párrocos para obtener firmas ${ }^{16}$ ya que tenía noticias de que en los medios rurales se empleaban medios violentos, como acusar desde el púlpito de ateos y herejes a aquellos que no firmaran. Romero Robledo se limitaba entonces a contestar que el Gobierno no tenía noticia concreta alguna de que se estuvieran cometiendo abusos, pero que se velaria porque no se ejerciese coacción sobre las conciencias de los ciudadanos.

igualmente genérica es la acusación que lanza Sagasta durante el discurso que sobre este artículo pronuncia en el Congreso el 12 de mayo, cuando se va a proceder a su votación; después de hablar de la influencia del profesorado, que obligaba - según él- a firmar a los niños en las escuelas, afirmaba: “... no quiero decir nada de la significación que puedan tener aquellas firmas adquiridas por los curas, que corren desalentados por los campos preguntando a los labradores con lágrimas en los ojos: ¿sois judios o cristianos? Y entonces los labradores, atónitos, contestan: Señor, cristianos. Pues si no sois judíos, firmad aqui contra los que quieren arrebataros la religión" "17.

${ }^{16}$ Diario de Sesiones del Congreso. Legislatura de 1876, págs. 356-357.

17 DSC Legislatura de 1876, pág. 1366. 
También desde la prensa adicta al gobierno - sobre todo desde el diario La Época, fuertemente "ministerial»- bien pronto comenzaron a lanzarse acusaciones sobre los abusos y coacciones con que se estaba llevando a cabo la campaña por los partidarios de la unidad católica, y desde el ministerio de la Gobernación se decidió enviar circulares a los gobernadores civiles de las provincias para que en su demarcación se prohibieran los abusos que se pudieran cometer en este asunto.

No se debieron dar instrucciones concretas, y las medidas tomadas por los alcaldes de los pueblos fueron absolutamente aleatorias. El diario El Español del 7 de abril publicaba un artículo titulado "Las peticiones católicas" donde se daba cuenta de las órdenes de los gobernadores afirmando que se pedía en casi todas ellas que procurasen los alcaldes evitar "cuanto puedan". que se suscriban peticiones en favor de la unidad católica. En el Diario de Sesiones del Congreso correspondiente al 12 de mayo de aquel año se registra la protesta del obispo de Teruel sobre la circular reservada expedida por el gobernador civil de aquella provincia, y numerosas son también las exposiciones que llegan a la Cámara expresando idénticas protestas.

En general, si hubo sacerdotes que se excedieron en su celo, también hubo alcaldes que se "pasaron" en el uso de sus atribuciones. La prensa católica fue recogiendo puntualmente a lo largo de los meses que duró la campaña todos los abusos de la autoridad de que tuvo noticia: destierro por orden del gobernador civil del párroco de S. Bernardo, Palencia, por hablar desde el púlpito a favor de la unidad religiosa ${ }^{18}$; en Andújar, secuestro de la exposición por el alcalde «en virtud de órdenes superiores" ${ }^{19}$; noticias de que en Pajarón (Cuenca) o en Murtas, no se han podido recoger las firmas por impedirlo las autoridades... ${ }^{20}$.

En las propias exposiciones se encuentran notas de los párrocos protestando de las dificultades que tuvieron por la oposición de las autoridades locales; desde aquellos que sólo dan noticia de que no se pudieron recoger más firmas porque to impidió el alcalde del pueblo ${ }^{21}$, hasta quien lo explica con pelos y señales ${ }^{22}$ : "Estando tomando las firmas llega orden del gobernador de Pontevedra, y se dijo y pregonó de cara en cara que nadie firmara /así de público/. Los paisanos que no habían firmado

\footnotetext{
18 La España, 10-11-1876.

19 El Español, 25-IV-1876.

20 Idem, 14-IV-1876.

21 Entre otros: Cobeña (Madrid), Leg. 644, exp. núm 61 y Ramaga (Salamanca), Leg. 658, exp. núm. 56. Archivo Senado.

${ }_{22}$ Exposición de Puentesampayo, Pontevedra. AS. Leg, 655, exp. núm. 70.
} 
fueron informados que las tales firmas eran para subirles los derechos a los curas y para los carlistas. El Gobernador ganó".

Se tiende por parte del Gobierno y de la prensa que le es adicta a descalificar el valor representativo de las exposiciones atendiendo no ya tan sólo a la coacción ejercida para obtener las firmas que las avalan, sino también poniendo en duda su autenticidad, o afirmando que en su mayor parte pertenecen a clérigos, mujeres y niños "los cuales no tienen el necesario discernimiento para comprender lo que a suscribir se les obliga» ${ }^{23}$.

Ecos de estas acusaciones aparecen en los textos de los documentos conservador, o en advertencias al final de los pliegos. En la exposición enviada por las mujeres de Cartagena, estas protestan de que "nos llamen instrumentos ciegos, perturbadores inconscientes de la paz doméstica" ${ }^{24}$; el párroco de Ullastrell, Barcelona, al certificar la autenticidad de todas las firmas declara que "de las señoras no he recogido, a pesar de estar casi todas dispuestas a firmar ${ }^{25}$; en otras exposiciones, y para mayor claridad, se separan en bloques distintos las firmas de los hombres y las de las mujeres: Rafá (Alicante), Frigiliana (Málaga), Ávila... El duque de Almenara Alta, al presentar en el Congreso ${ }^{26}$ una exposición de las islas de Mallorca, Menorca e Ibiza, avalada por 29.603 firmas informaba que a...de las cuales no hay ninguna perteneciente a individuos del estado eclesiástico ni a las señoras de aquellas islas, que han formulado otra exposición por sí solas".

Para evitar suspicacias, en muchas exposiciones se certificaba la autenticidad de las firmas, saliendo garante de ello el propio cura, aunque en algunos casos dan fe de que son espontáneas y originales el propio alcalde o el juez municipal ${ }^{27}$. $Y$ es que un caso llamativo de posible falsedad de documento había saltado a la prensa en los inicios de la campaña. El 27 de enero una comisión de señoras de la nobleza presentaba al Rey una exposición pidiendo la unidad católica que iba avalada por mas de 60.000 firmas de señoras de toda España. A los dos días el diario El Diario Español protestaba de la autenticidad de aquellas firmas al comprobar que entre ellas figuraba el de la marquesa viuda de Santiago, ya fallecida. En el diario La España se salía en defensa de la

${ }^{23}$ La España, 4-IV-1876,

${ }^{24}$ Exposición de mujeres de Cartagena. AS leg., 650, exp. $\mathrm{n}^{\circ} 26$.

${ }^{25}$ Exposición de Ullastrell. AS Leg., 675, exp. n. 2 (5).

${ }^{26}$ DSC Legislatura 1876-1877, pág. 1256.

27 Exposición del pueblo de La Junquera, arz. Málaga. AS leg., 673, exp.. 11 
honorabilidad de aquella exposición ${ }^{28}$ replicando que si la firma figuraba en ella era porque se había comenzado a recabar adhesiones desde muchos meses atrás, y añadia sarcásticamente: “...tenga por cierto nuestro colega que si se pudieran comprobar también los votos de muchos diputados como las firmas de las señoras que piden la unidad católica, tenemos la seguridad de que algunos no llegarian a tomar asiento en el Congreso".

\section{RESULTADOS DE LA CAMPAÑA}

Hasta el 16 de mayo de 1876, fecha de recepción de las últimas exposiciones que se recibieron en el Congreso de los Diputados, habian sido consignadas en el Diario de Sesiones de esta cámara un total de 4.071 escritos en favor de la unidad católica, y diez en contra de ella, con su correspondiente pase a la Comisión de Peticiones creada a tal efecto. La documentación conservada en su archivo es sólo una pequeña parte, pues sólo han podido documentarse 347 exposiciones en favor de la unidad religiosa y otras cuatro pidiendo el mantenimiento de la libertad de cultos.

Las cantidades consignadas en el Diario de Sesiones de esta cámara no son desde luego exactas, por cuanto en dicho Diario sólo se registra en algunas ocasiones el número de firmas enviadas desde una determinada provincia, sin concretar los pueblos a los que corresponden, en otras, sólo se menciona el número de exposiciones recibidas, sin hacer mención al número de firmas que las avalan o a la cantidad de pueblos que las remiten. Con todo, esta cantidad resulta bastante aproximada a la que debia ser la cifra real a la vista de las cifras que se están dando en la prensa.

Así, por ejemplo, el diario El Español, que desde el 24 de abril anterior venía insertado en su primera página una relación de todas las exposiciones que se presentaban a esta cámara pidiendo la unidad católica, llevada contabilizadas 4.060 exposiciones -cifra sensiblemente pareja a la anteriormente mencionada - avaladas por un total de 1.440 .839 firmas en el día 12 de mayo, fecha en que la sección se interrumpe al haber tenido lugar la votación sobre el artículo 11 en la

${ }^{28}$ La España, 29-1-1876. 
Cámara de los Diputados con un resultado claramente adverso para la unidad católica.

Es en el Archivo del Senado donde se encuentra el grueso de la documentación existente sobre este tema. Se trata de un total de 2.157 exposiciones diferentes, correspondientes a 2.073 pueblos, con 496.402 firmas. Entre todas ellas no hay ninguna favorable a la libertad de cultos, como ocurría en el archivo del Congreso ${ }^{29}$.

Teniendo en cuenta las variables existentes según se combinen las tres fuentes que se han manejado -archivo del Congreso y del Senado, Diario de Sesiones del Congreso y prensa de la época- se obtiene para esta campaña un número de firmas que oscila alrededor del millón y medio, mientras que el número de pueblos que las remiten está en torno a los 5.000 .

Para juzgar la importancia relativa de esta campaña de protesta contra la tolerancia religiosa, el mejor procedimiento resulta ser la comparación con los resultados del movimiento análogo producido siete años antes, cuando se debatió la constitución de 1860 que reconocía la libertad religiosa en detrimento de la unidad católica.

Está fuera de toda duda el drástico descenso del número de firmantes entre una y otra convocatoria, ya que si la protesta católica del año 1869 la avalan las firmas de 3,3 millones de personas ${ }^{30}$, ahora, siete años más tarde, y pese al previsible aumento de población, la avalan entre 1,2 y 1,7 millones de firmas (horquilla que contempla como mínimo sólo las cifras dadas en el Diario de Sesiones del Congreso, y como máximo las recogidas en la Prensa y en el archivo del Senado), o lo que es lo mismo: se ha pasado del 20 por 100 del censo favorable a la unidad religiosa al 7-10 por 100. Es decir, en el mejor de los casos, los resultados de esta campaña se han reducido a la mitad. Este dato queda corroborado por el número de pueblos que envían peticiones: 10.110 en 1869 frente a 5.239 a 1876, sumando los datos del Congreso y del Senado.

${ }^{29}$ Todos estos documentos estuvieron anteriormente depositados sin catalogar en el Archivo del Congreso hasta el año 1986, en que al ser creado el archivo del Senado fueron trasladados alli. Las exposiciones aparecen agrupadas por arzobispados, diócesis o provincias, y repartidas en 17 legajos de la sección Comisión de Peticiones, Legislatura 1876, legs. $n{ }^{\circ} 649$ al 675.

${ }^{30}$ Rodriguez, J. Jerónimo, La sociedad española ante la libertad religiosa, 1869. Valoración cuantitativa. Memoria de Licenciatura. Departamento de Historia Contemporánea. Madrid, UNED, 1977. 
Este claro retroceso en el volumen de la protesta puede tener varias causas, entre otras, y no la menor, que la Iglesia no contó esta vez con ningún apoyo laico - ni siquiera la Asociación de Católicos, en funcionamiento desde 1869- y hubo de hacer frente a la organización de la campaña con sus propios medios. Esta circunstancia, junto con la sensación en la opinión pública de que la batalla estaba perdida de antemano, a la vista del decidido apoyo gubernamental a la liberalización religiosa, pudo llevar a la inhibición de una buena parte de los católicos ante esta iniciativa de las jerarquias eclesiásticas. 